\title{
UNIQUE PERSPECTIVES
}

ON A TRANSFORMING ENERGY ECONOMY

2014 ANNUAL REPORT

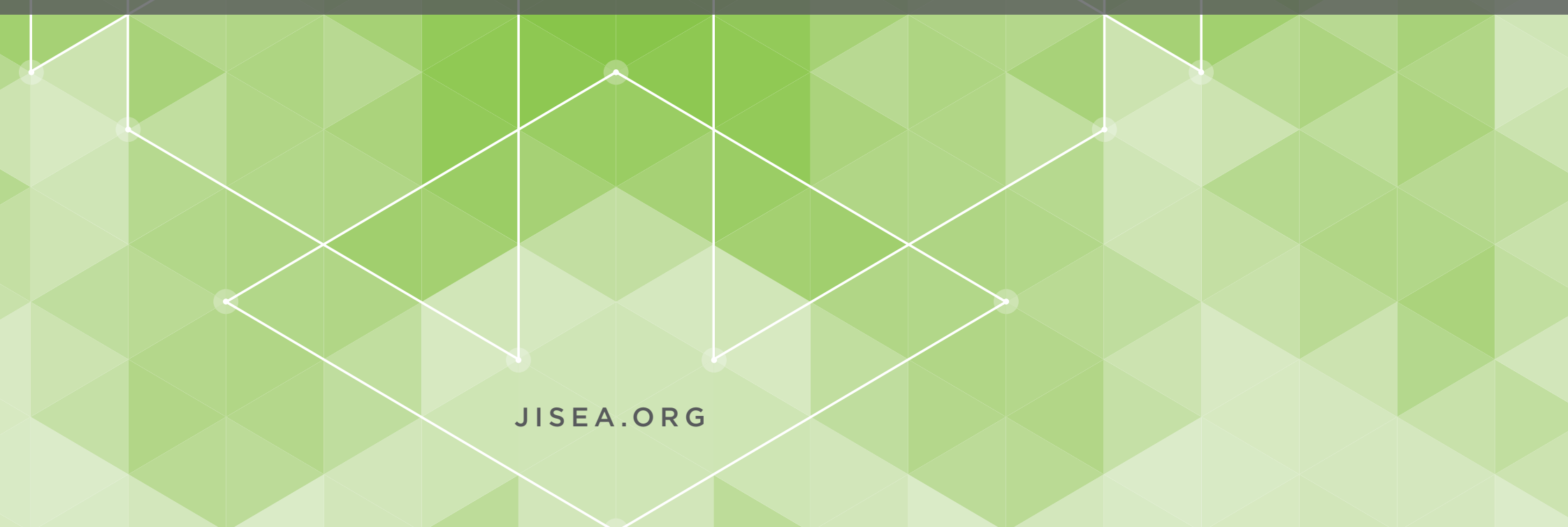




\section{WHAT MAKES JISEA UNIQUE?}

UNIQUE PERSPECTIVES.

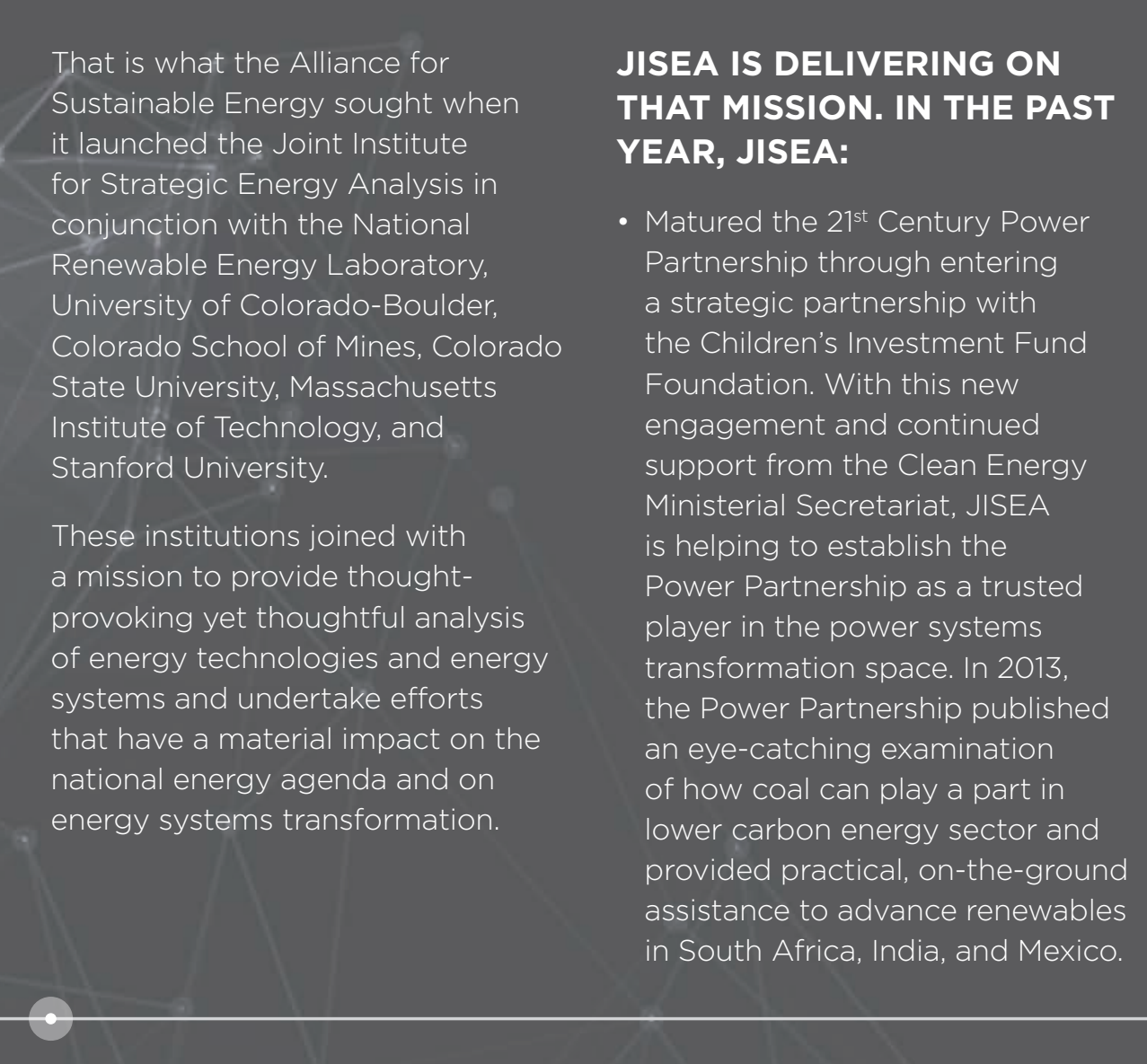

$8=$

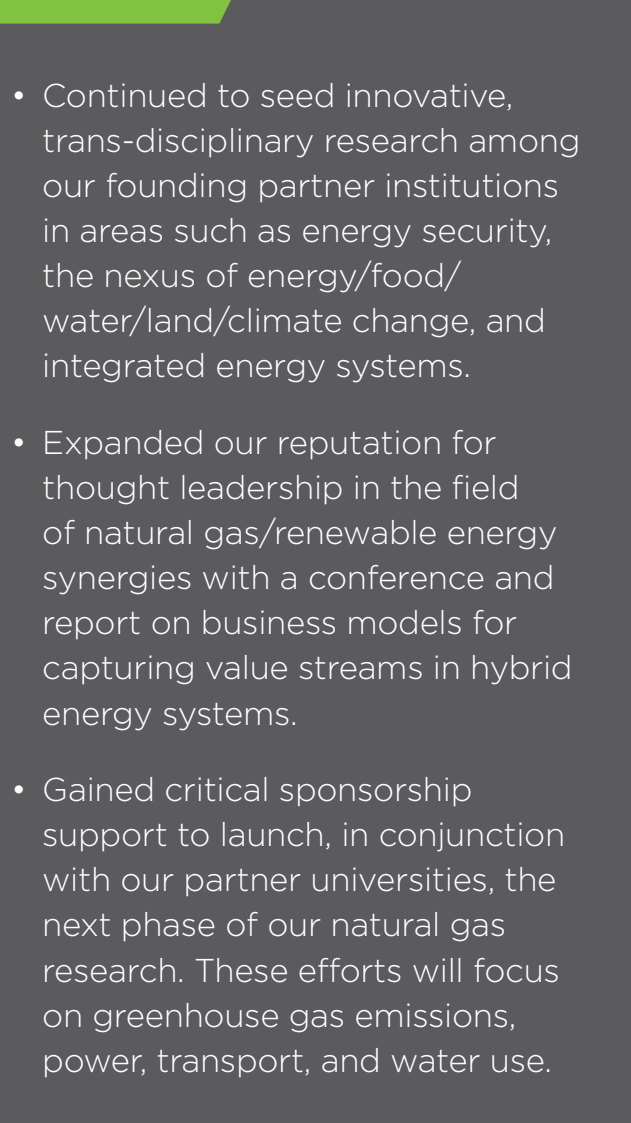

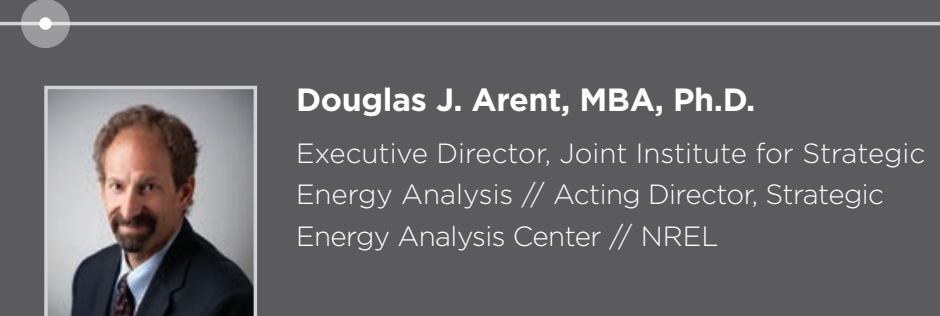
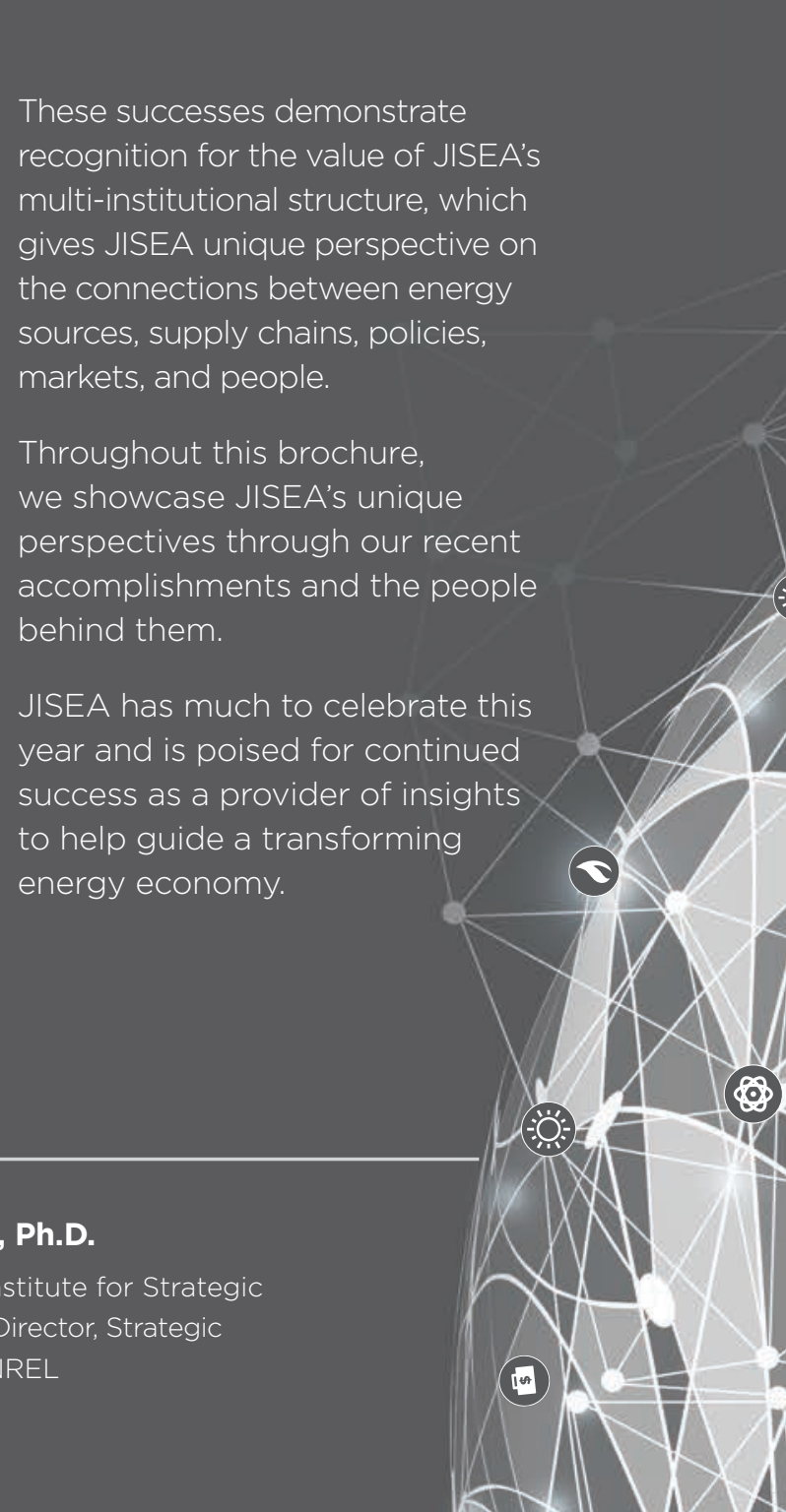

CONTENTS

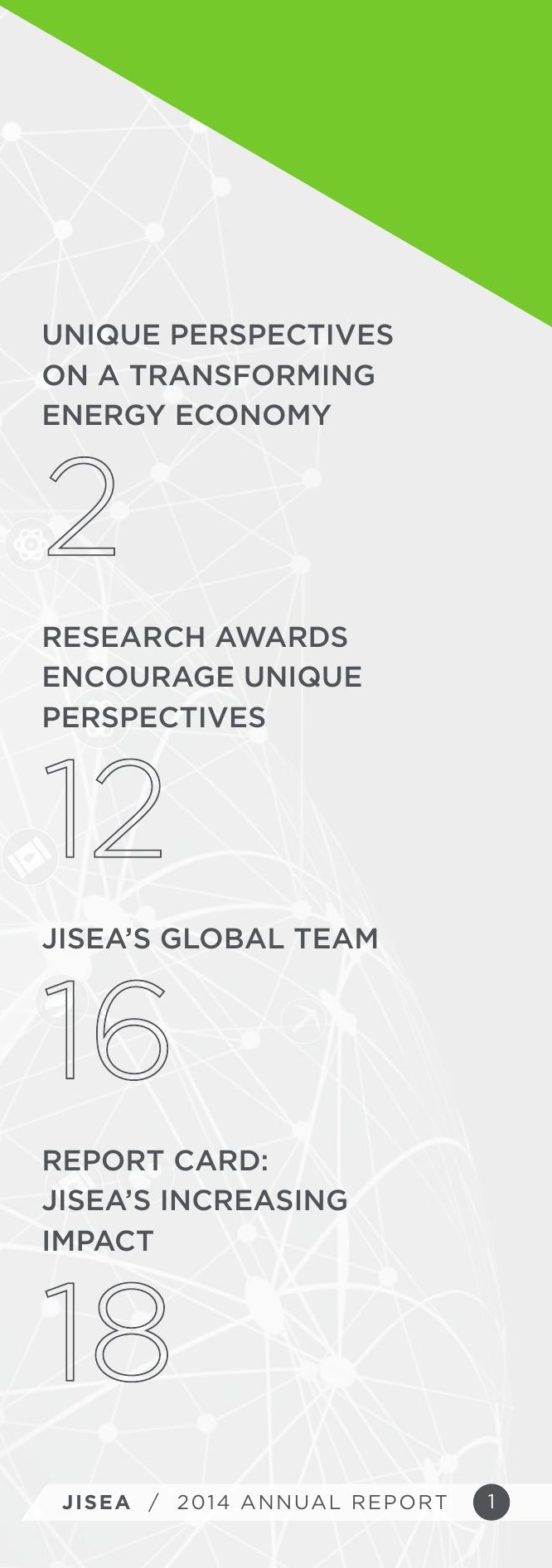





\section{SLASHING FUEL CONSUMPTION COMES WITH A PRICE}

Excerpted from NPR's All Things Considered

When National Public Radio's All Things Considered wanted to know if it is possible to create a U.S. electric system that provides stable power with as much as $80 \%$ renewable resources, the program turned to JISEA's Doug Arent for answers.

Governments around the world are seeking a new agreement to address anthropgenic climate change. Reducing carbon output by up to $80 \%$ by mid-century from sources like coal, oil and natural gas, which emit carbon dioxide into the air, is a critical component of any response strategy.

Nations are far from that ambitious path. There are big political and economic challenges. But technologists do see a way-at least for the United States-to achieve that goal.

Nowhere is that aspiration clearer than at the National Renewable Energy Laboratory.

People have been dreaming about clean energy for decades. And for decades, the world has relied overwhelmingly on the much cheaper fossil fuels. Coal, oil and natural gas made up 82 percent of total energy consumed 25 years ago, and they still make up 82 percent of the world's energy diet today.

To find out what it would take to budge from that mark, I sat down with the National Renewable Energy Lab's Douglas Arent.

Arent co-authored a major study to look at a piece of this challenge. It asked whether the United States could move away from coal and gas, and instead rely on wind, solar and other renewable energy supplies for at least 80 percent of the nation's electricity by the middle of this century.

Not to say it would be easy.

"The grid would have to be much more flexible," Arent says. "The utility model of the future would have to look different. And of course, in the economically ideal case, we would build much more transmission."

Those new transmission towers might prove too expensive, or they might generate local opposition.

If that happens, Arent says, we'd

"Our results, from a technical nature, show that you could meet demand every hour of the year, with up to 80 percent of it coming from renewable resources," Arent says.

"Our results, from a technical nature, show that you could meet demand every hour of the year, with up to 80 percent of it coming from renewable resources," Arent says. need to find a way to store a huge amount of renewable power so it can be used when it's needed.

"What we found was that there were many pathways, and there

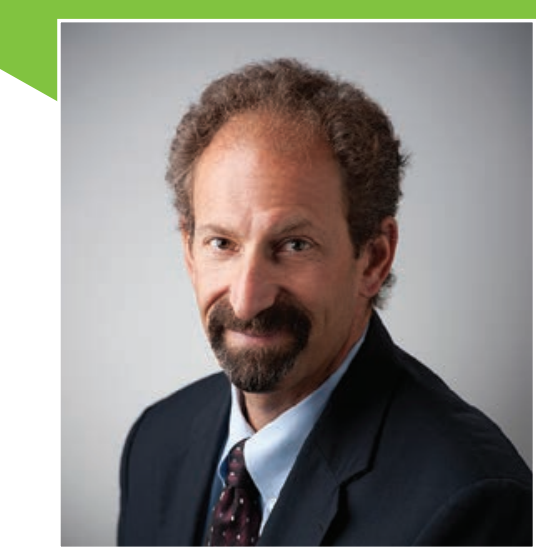

Douglas Jay Arent, MBA, Ph.D. Executive Director

Doug Arent specializes in strategic planning and financial analysis competencies; clean energy technologies and energy and water issues; and international and governmental policies. In addition to his NREL responsibilities, Arent is a Senior Visiting Fellow at the Center for Strategic and International Studies. Arent was appointed as a Coordinating Lead Author for the $5^{\text {th }}$ Assessment Report of the Nobel Prize winning Intergovernmental Panel on Climate Change (IPCC) and serves on the National Research Council Committee to Advise the U.S. Global Change Research Program. 


\section{JISEA'S GLOBAL TEAM}

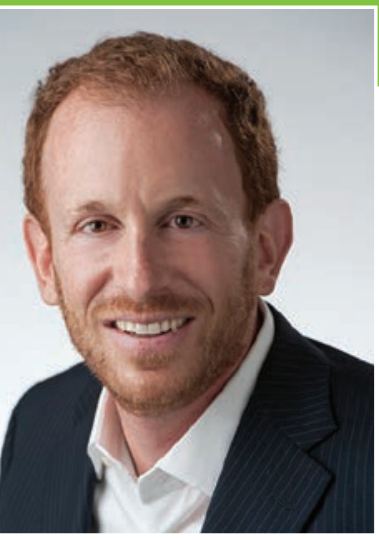

Morgan Bazilian, Ph.D.

Deputy Director

Morgan Bazilian joined JISEA with two decades of experience in the energy sector ranging from

upstream oil and gas policy to the design of fiscal instruments to promote clean energy. Before joining JISEA, Bazilian was the Senior Advisor to the DirectorGeneral of UNIDO on internationa energy and climate policy. In this role he helped shape the United

Nations approach to energy for development and managed the UN's interagency energy mechanism-UN-Energy. wasn't a red flag that said it was impossible, at least at the level that we looked at it," Arent says.

At Stanford University, Sally Benson heads the Global Climate and Energy Project. She challenges her students to think of reducing emissions from all energy sources-not just electricity, but transportation fuels, gas furnaces and industrial processes.
The solution the students inevitably arrive at requires steady, reliable and large-scale sources of clean energy. It also means producing a substantial amount of nuclear power.

"It's definitely an all-of-the-above strategy," Benson says. "You have to do all of them at a really significant pace, and you need to be reducing carbon emissions and your energy use."
So, is she optimistic?

"I think there's lots of good news on the technology side, and I think [many of] the smartest engineers and scientists at universities around the world ... are focused on this challenge," she says. "So from that perspective, I am quite optimistic."

\title{
LINKING ENERGY INDEPENDENCE TO ENERGY SECURITY
}

Adapted from paper published in International Association of Energy Economics Energy Forum.

\author{
"Energy independence" is an appealing goal, but given realities of domestic \\ energy markets and geopolitics, it may not be a realistic one.
}

Dramatic changes in oil and gas production in the United States have resurrected interest in "energy independence." This attraction likely stems in part from a connotation that "independence" equals resiliency and stability of energy services without risk of volatility.

However, both domestic energy issues and geopolitics are considerably more interrelated than this argument allows. In addition, the vocabulary used is often imprecise. We argue that although politically seductive, the idea of energy independence can distract from sound decision making in the energy sector.

The case against relying on energy independence as a policy prescription tends to look at the end goals of energy policy, and describes resiliency and stability of energy services not as ends themselves, but rather as means of economic growth, innovation, and social well-being.
Some degree of enthusiasm is warranted. In the United States, energy independence is commonly defined in terms of the degree of reliance on imports from outside North America, and falling imports have made independence appear attainable. The past five years have witnessed a sea change in the proven reserves and the production of oil, natural gas, and natural gas liquids in the United States.

A far larger set of considerations are critical to inform energy policy. 
0

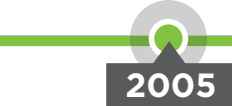

The concepts and methodologies from the "energy security" literature provide firmer grounding for policymaking.

Energy security requires a rigorous aggregation of dozens of variables that impact energy flows in the real world. John Elkind in 2010 argued that energy security is composed of:

\section{- Availability-the ability for} consumers and users to secure energy

- Reliability-the extent that energy services are protected from disruption

\section{- Affordability-low or equitable} and stable prices relative to income
- Sustainability-minimizing social, environmental, and economic damage.

The simplifications that come with the energy independence frame can promote sub-optimal policy choices if they fail to acknowledge the complexity of energy security and wider considerations of geopolitics and markets.

The future could bring more globally interdependent markets and systems. As a result, the pillars of robust U.S. energy policy could include an embrace of global partners, a wise optimization of the bounty of oil and gas in North America toward sustainable patterns of consumption and use, and close consideration of the possible synergies between fossil fuels and renewable energy resources.
Google searches for the term "US energy independence" begin spiking in early 2012 , reflecting a resurging interest in the topic. 
With this study and our larger body of work focusing on natural gas, JISEA offers policymakers and investors a solid analytical foundation for decision making. (i) LEARN MORE http://www.sciencemag.org/ content/343/6172/ 733.summary

\section{METHANE EMISSIONS FROM NATURAL GAS SYSTEMS INDICATE NEW PRIORITIES FOR NATION}

Study findings published in the journal Science.

Because natural gas emits less carbon dioxide during combustion than other fossil fuels, it has been touted as a 'bridge' fuel to a lower carbon energy system. But a new study published in the journal Science says that the total impact of switching to natural gas depends heavily on leakage of methane $\left(\mathrm{CH}_{4}\right)$ during the natural gas life cycle and finds that current evidence suggests leakages are larger than official estimates.

The article presents a first effort to systematically compare North American emissions estimates at scales ranging from device-level to continental atmospheric studies. Work was organized by Novim with funding from the Cynthia and George Mitchell Foundation and led by Stanford University's Adam Brandt. "Methane Leakage from North American Natural Gas Systems" features JISEA and JISEA founding partner members among its international team of authors.

"Recent life cycle assessments generally agree that replacing coal with natural gas has climate benefits," said Garvin Heath, a senior scientist at NREL and a lead author of the report. "We identified cause for concern but found that system-wide leakage is unlikely to be large enough to disfavor coalto-natural gas substitution."

"With this study and our larger body of work focusing on natural gas, JISEA offers policymakers and investors a solid analytical foundation for decision making," said Doug Arent, co-author to the study.

\section{AMONG OTHER FINDINGS OF} THE RESEARCH:

- Official inventories of methane leakage consistently underestimate actual leakage.
- Evidence at multiple scales suggests that the natural gas and oil sectors are important contributors.

- Independent experiments suggest that a small number of "super-emitters" could be responsible for a large fraction of leakage.

- Recent regional atmospheric studies with very high emissions rates are unlikely to be representative of typical natural gas system leakage rates.

- Hydraulic fracturing is not likely to be a substantial emissions source, relative to current national totals.

- Abandoned oil and gas wells appear to be a significant source of current emissions. 


\section{BUSINESS OPPORTUNITIES FOR UNITING NATURAL GAS AND RENEWABLES ABOUND AT SYSTEM AND SECTOR LEVELS}

To support the U.S. need for cleaner energy sources now and in the long term, a study by JISEA identifies compelling business models that build from the synergies of two abundant, domestic forms of energy: natural gas and renewable energy.

Natural gas and renewable energy each contribute to economic growth, energy independence, and carbon mitigation, sometimes independently and sometimes collectively. In a growing body of work, JISEA examines ways these two domestic forms of energy can work in greater concert."
A 2014 paper, Exploring the Potential Business Case for Synergies between Natural Gas and Renewable Energy, identifies revenue opportunities that emerge from systems-level perspectives in "bulk energy" (large-scale electricity and natural gas production, transmission, and trade) and four "distribution edge" subsectors: industrial, residential, commercial, and transportation end uses.

"To advance a cleaner, decarbonized energy system, we have to look at energy and economic systems in new ways. With this study, JISEA provides a valuable and unique perspective on collaboration rather than competition between natural gas and renewables, and practical insights that can help spur the clean energy economy," said former Colorado governor Bill Ritter, Jr., director of the Center for the New Energy Economy (CNEE) at Colorado State University. CNEE and JISEA co-hosted a workshop to gather expert input on the business models for gas and renewables.

\section{ADVISORY COUNCIL}

JISEA is forming an external Advisory Council to help ensure that its work has a material impact on national and global energy issues. The council will also provide advice on how to strengthen the distinctiveness and value of JISEA's capabilities. Initial members include:

\section{Joan MacNaughton}

Executive Chair, World Energy Trilemma, World Energy Council

\section{Bill Ritter}

Director, Center for the

New Energy Economy, Colorado State University

\section{Katherine Sierra}

Senior Fellow, The Brookings Institution

\section{(i) LEARN MORE JISEA.org/natural_gas.cfm nrel.gov/docs/fy14osti/ 60052.pdf}


JISEA looks beyond either/or solutions for

decarbonizing the energy sector and engages in the practical work of achieving that goal in an "all of the above" world.

(i) LEARN MORE sciencedirect.com/science/ article/pii/s0196890413007516

HYBRID NUCLEAR/RENEWABLE SYSTEMS CAN PROVIDE SECURE, RELIABLE, AFFORDABLE, LOW-CARBON ENERGY

In a paper published in Energy Conversion and Management (Vol 78, Feb. 2014), JISEA explores a potential concept for providing low-carbon and secure, reliable, affordable energy-hybrid operation of nuclear reactors coupled with renewable energy technologies and industrial processes in a single facility.

"As energy systems move toward lower carbon energy, significant additions of variable renewable generation such as wind and photovoltaic power are likely," said JISEA's Morgan Bazilian, co-author of the article.
"Continued integration of variable renewable resources drives the need for flexible generation to accommodate fluctuations in supply and demand."

Advanced informatics, energy management systems, and forecasting are enabling new innovation in integrated plant design and power system operations and can be utilized to design new types of hybrid energy systems that:

- Allow traditional base-load systems to generate economical load-following power
- Improve grid flexibility and allow for multiple types of ancillary services

- Produce additional commodities such as fuels for the transportation sector.

Authors identified opportunities, interconnections, and needs, and explored interface and systemlevel issues including ownership, regulatory, design, construction, and operational issues. 


\section{1st Century \\ POWER \\ PARTNERSHIP \\ FLEXIBLE COAL PLANTS CAN PLAY A PART IN 21 ${ }^{\text {ST }}$ CENTURY POWER SYSTEMS}

Accelerating the transformation of power systems

The $21^{\text {st }}$ Century Power

Partnership aims to accelerate the global transformation of power systems. The multilateral effort of the Clean Energy Ministerial serves as a platform for publicprivate collaboration to advance integrated policy, regulatory.

financial, and technical solutions for the large-scale deployment of renewable energy in combination with deep energy efficiency and smart grid solutions.

As the operating agent for the Power Partnership, JISEA implements Power Partnership activities based on guidance from the Clean Energy Ministerial, the United Nations, and other partners and stakeholders. JISEA is also engaged on behalf of the Power Partnership in 'on the ground' activity to increase renewable penetration in South Africa, Mexico, and India.

LEARN MORE

21stCenturyPower.org
Globally, new economic and political circumstances are reshaping power systems in favor of those that operate with greater flexibility and efficiency and incorporate renewable energy and demand response. Coal, which is widely perceived to provide only baseload power generation, remains a critical component in most power systems. Coal generation plants can be modified to fit within the new power sector and be a part of a cleaner energy system.

A new report, Flexible Coal: Evolution from Baseload to Peaking Plant, summarizes the findings from a coal generating station that has been modified to operate more flexibly, with the ability to cycle on and off daily and run at low generation levels. The report was prepared by analysts from NREL and Intertek for the $21^{\text {st }}$ Century Power Partnership.

"This study proves that coal can be part of a power system with high levels of renewable energy," said NREL's Jaquelin Cochran, a lead author of the report. "Coal plants can be modified to respond to the changing output of renewable energy and run at low levels when renewable electricity generation is high but demand is low, such as at night. There is a cost to this flexibility, but these costs can be minimized with strategic modifications and maintenance.

The power sector's transition to greater penetration levels of renewable energy, demand response, and other emerging technologies requires flexibility in terms of power generation; it will favor plants that can cycle on and off multiple times per day and be turned down to low levels.

The ability of other coal plant operators to replicate the flexibility of the studied plant will be instrumental in valuing coal in an increasingly low-carbon energy system, according to the study.

"Older coal units can still serve a purpose if they are operated flexibly," said Cochran. i LEARN MORE nrel.gov/docs/fy14osti/ 60575.pd

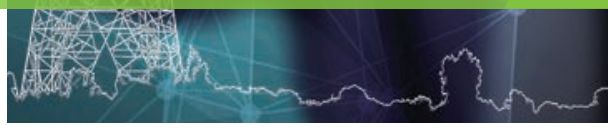

\section{MARKET EVOLUTION:}

Wholesale Electricity Market Design for $21^{\text {st }}$ Century Power Systems

The $21^{\text {st }}$ Century Power Partnership established thought leadership with this review of wholesale power market designs in use and under consideration to ensure adequacy, security, and flexibility in a landscape of significant variable renewable energy.

(i) LEARN MORE nrel.gov/docs/fy14osti/ 57477.pdf 


\section{ENERGY SYSTEMS INTEGRATION: A CONVERGENCE OF IDEAS}

Our energy system includes not only renewable, nuclear, and fossil energy sources but also electrical, thermal, and fuel energy pathways that convert and deliver energy services at different physical scales. Interactions and interdependencies are increasing among the pathways and across the physical scales of the energy system as well as

Energy systems integration is more than a trend.

It is a critical research and development area that will underpin the energy system of the future.

between the energy system and other systems such as data and information networks. Energy systems integration (ESI) enables the effective analysis, design, and control of these interactions and interdependencies along technical economic, regulatory, and social dimensions. By focusing on the optimization of energy systems across multiple pathways and scales, we can better understand and make use of potential cobenefits that increase reliability and performance, reduce cost, and minimize environmental impacts.
JISEA and its partners recognize the growing importance of ESI as a critical multidisciplinary, multifaceted research and development area that will underpin the energy system of the future. We support NREL's development of a core competency to drive the development of the next generation of systems integration, simulation, operation, and controls and inform future energy system architectures, policies, and investments. NREL is assembling critical analytical and physical capabilities to address ESI with investments in the new, state-of-the-art Energy Systems Integration Facility and national and international work to highlight challenges and opportunities.

Headquartered on NREL's $327-$ acre campus, JISEA benefits from access to NREL's researchers and research facilities, including the Energy Systems Integration Facility. This Energy Department user facility is the nation's first to help both public and private sector researchers scale up promising clean energy technologies and test how they interact with each other and the grid at utility scale. 


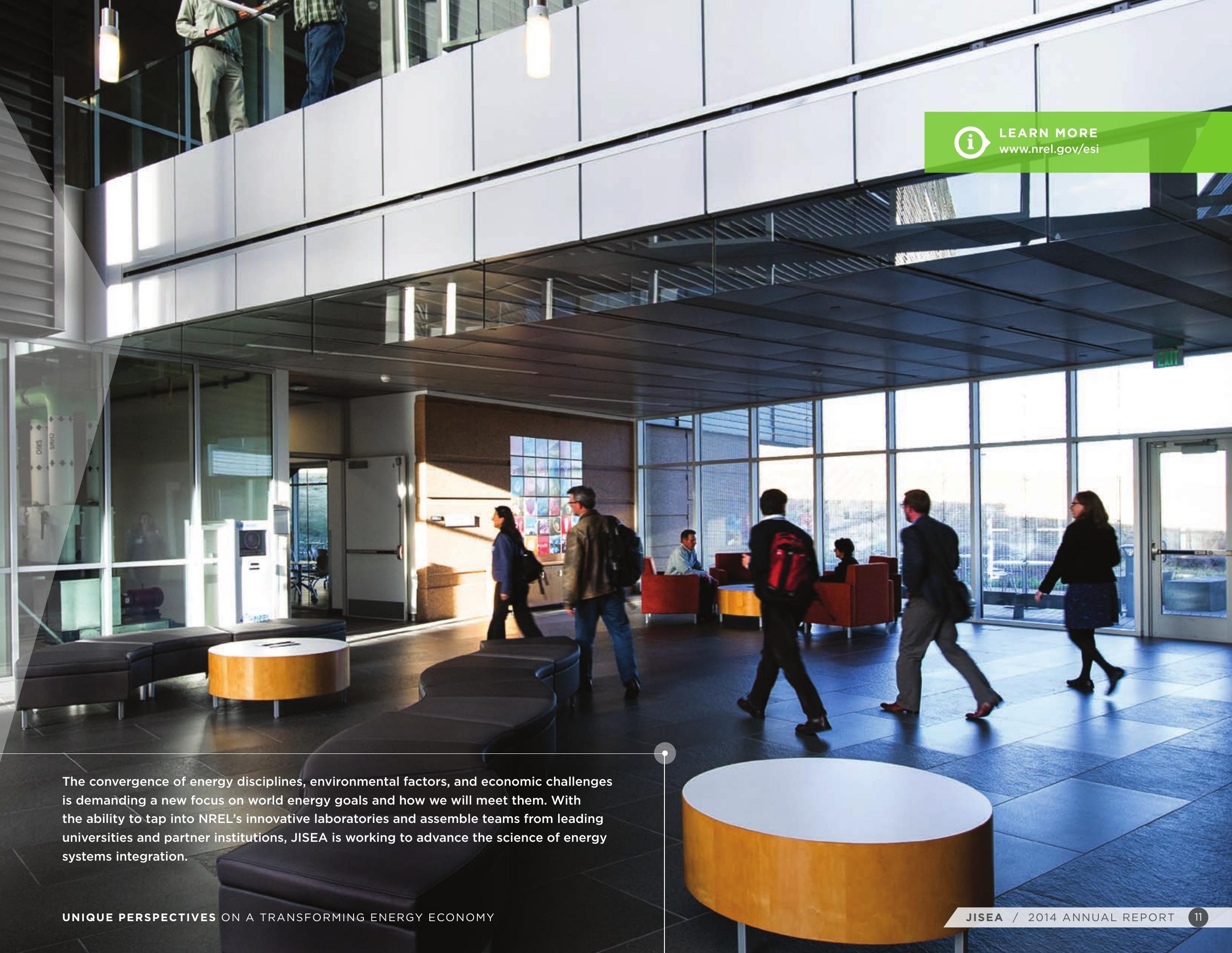




\section{RESEARCH AWARDS}

ENCOURAGE UNIQUE PERSPECTIVES

Through the Innovative Research Analysis Award Program (IRAAP), JISEA has provided nearly $\$ 1$ million to research teams drawn from JISEA partner institutions for collaborative, multidisciplinary energy analysis projects.

\section{PUBLISHED AS PEER-REVIEWED JOURNAL ARTICLES AND TECHNICAL REPORTS, RESEARCH} FUNDED THROUGH JISEA'S IRAAP PROGRAM:

- Emphasizes the environmental, economic and financial, policy, technological, and social and behavioral aspects of energy systems
- Encompasses an integrated systems perspective

- Considers the implications of findings in economic, social, and environmental terms
- Applies at local, domestic, and international scales

- Leads to significant global impacts on energy sector transformation. 

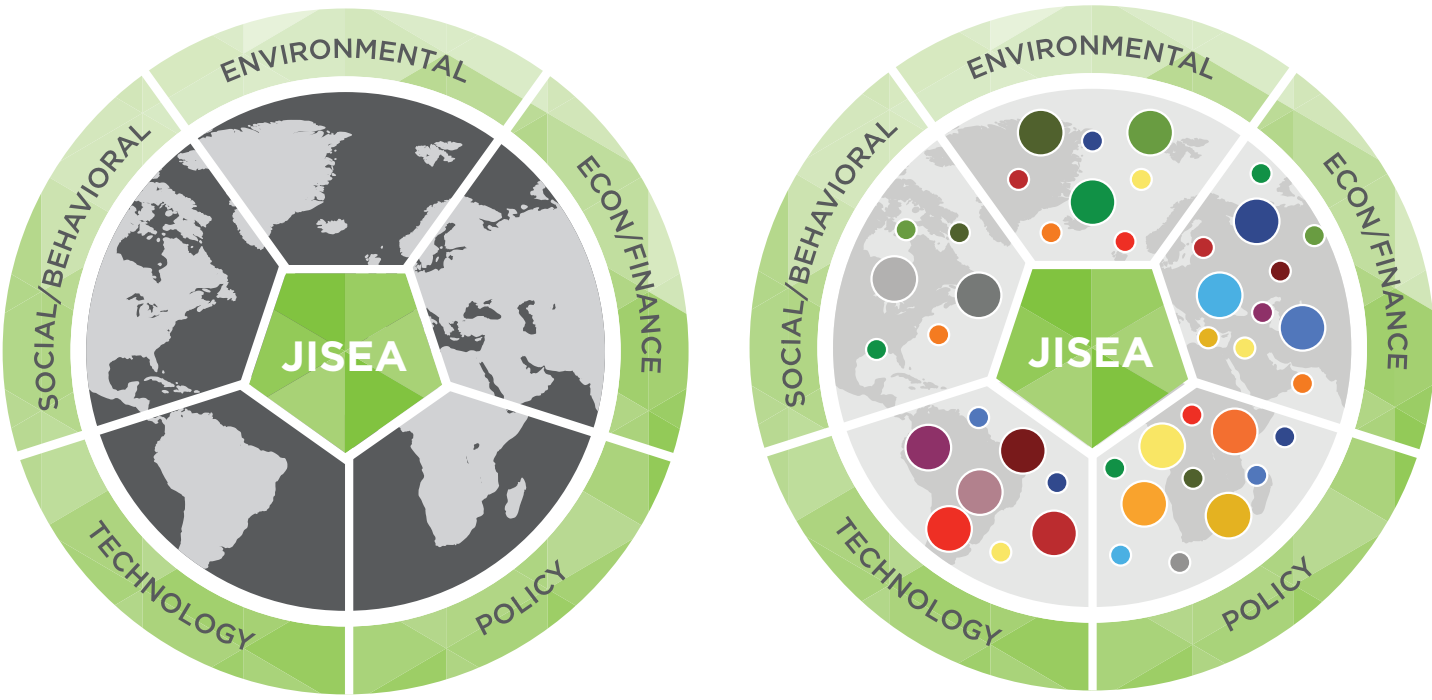

- Energy $\mathrm{H}_{2} \mathrm{O}$ Nexus

- Energy and Water

- Marginal Lands

- Financial Models

- GIS Optimization

Ancillary Markets

- Model Integration

Waste to Energy

- Sustainability Analysis

- Energy-Specific Models

- Microgrids

- $\mathrm{CO}_{2}$ Mineralization

- Nuclear and RE

- Lo-Temp Geotherma

- Hydropower

High RE and DR

- EE Retrofits

Our balanced portfolio of projects emphasizes environmental, economic and financial, policy, technological, and social and behavioral aspects of energy systems. The projects also range in geographic scope.

\section{IRAAP PROJECTS WITH \\ ENVIRONMENTAL EMPHASIS}

\section{Energy-Water Nexus in a Drying}

West: A Case Study Analysis and Methodology

\section{COLLABORATORS}

Colorado State University, University

of Colorado at Boulder, NREL

\section{RESEARCH GOAL}

Inform long-term energy and

transmission planning strategies.
Toward an Improved Methodology for Comparing Water-related Impacts of Electricity Generation:

A Preliminary Analysis of

\section{Concentrating Solar Power Data}

\section{COLLABORATORS}

Stanford University, University of Colorado at Boulder, NREL

\section{RESEARCH GOAL}

Develop more comprehensive and accurate water quality and water quantity metrics for use by energy system planners and regulators.

\section{Renewable Energy Potential} on Marginal Lands in the United States

\section{COLLABORATORS}

Stanford University, NREL

\section{RESEARCH GOAL}

This study, the first to take a detailed look at U.S. marginal lands and their potential for renewable energy development, provides policymakers and industry developers with valuable information to guide strategic decisions.
JISEA'S GLOBAL TEAM

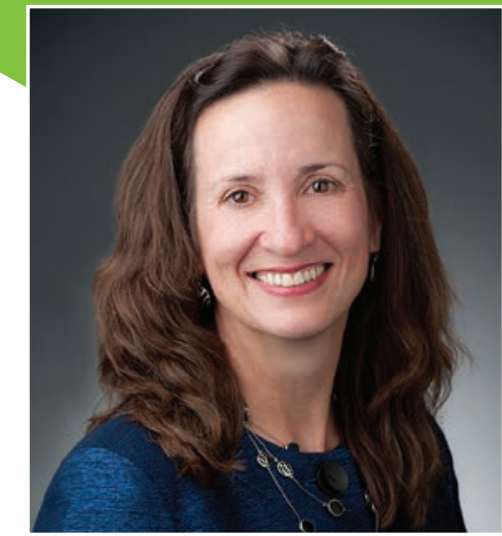

Patricia Statwick

Program Administrator

Patricia Statwick works to develop implement, and manage JISEA programs, including the Innovative Research Analysis Award Program. She provides project management assistance for projects ranging from topical scoping studies to international program operations. Statwick recently received a master of applied science degree in environmental policy management, with a concentration in energy and sustainability, from the University of Denver. She has an MBA from Northwestern University and a bachelor of arts from the University of Notre Dame. 


\section{IRAAP PROJECTS WITH}

TECHNOLOGY EMPHASIS

\section{Verifiable Decision-making}

Algorithms for Reconfiguration

of Electric Microgrids

\section{COLLABORATORS}

Colorado State University,

University of Colorado at Boulder

\section{RESEARCH GOAL}

Discover new algorithms for reconfiguration of electric power microgrids in order to accelerate the penetration of renewables in the grid.

Impact of Alkalinity Sources on the Life Cycle Energy Efficiency of $\mathrm{CO}_{2}$ Mineralization Technologies

\section{COLLABORATORS}

Massachusetts Institute of

Technology, Stanford University

\section{RESEARCH GOAL}

Assess the usefulness of several potential alkalinity sources,

providing findings usable in life

cycle assessments of mineralizationbased $\mathrm{CO}_{2}$ capture systems.
A Combined Nuclear and

Renewable Solution to

Decarbonizing the Electric Sector

COLLABORATORS

Colorado School of Mines, NREL

\section{IN-KIND COLLABORATOR}

University of Wisconsin at Madison

RESEARCH GOAL

Investigate the potential

compatibility of a high renewable energy grid with load-following nuclear power plants.

Integration of Low-Temperature Geothermal Resources with Other Power Generation Technologies to Improve System Performance and Resource Utilization

\section{COLLABORATORS}

Colorado State University, NREL

RESEARCH GOAL

Using a techno-economic analysis, identify promising applications for low-temperature geothermal resources.
Improving Hydropower Operational

Models for Integrating High

Penetrations of Renewable Energy

COLLABORATORS

University of Colorado at Boulder, NREL

RESEARCH GOAL

Explore the contribution that a more accurate representation of hydropower could have to the electric system and the integration of variable generation.

\section{IRAAP PROJECTS WITH ECONOMIC AND \\ FINANCIAL EMPHASIS}

\section{Financial Models for Electric}

Utility Market Transformation

COLLABORATORS

Colorado State University, NREL

IN-KIND COLLABORATOR

Rocky Mountain Institute

RESEARCH GOAL

Identify the business models that utility customers are using to support distributed generation (DG), and quantify the effect of DG on traditional utility business models.
A GIS-based Mapping and Optimization Tool to Aid Siting, Design and Assessment of Utility Scale Energy Development

COLLABORATORS

NREL, Stanford University

RESEARCH GOAL

Develop a proof-of-concept,

Web-based GIS tool that evaluates multiple user-defined criteria in an optimization algorithm to inform site selection decisions.

\section{Emerging Ancillary Service} Markets in Non-restricted Regions of the Western Power Grid

COLLABORATORS

University of Colorado at Boulder, NREL

IN-KIND COLLABORATOR

RASEI

RESEARCH GOAL

Provide advanced technical, market, and legal-regulatory analysis of needs and barriers with respect to the proposed regional energy imbalance market for the western interconnection. 
IRAAP PROJECTS WITH

\section{POLICY EMPHASIS}

Creation of an Energy Specific Computable General Equilibrium Model to Analyze State Level Policy

COLLABORATORS

Colorado State University, NREL

RESEARCH GOAL

Create a computable genera equilibrium model that can help state and federal decision makers assess far reaching impacts of investments in different energy technologies.

Waste Not, Want Not: Analyzing the Economic and Environmental Viability of Waste to Energy Technology for Site-specific Optimization of Renewable Energy Options

COLLABORATORS

University of Colorado at Boulder, NREL

RESEARCH GOAL

Investigate the environmental, policy, economic, and technical factors that have contributed to the success of waste-to-energy technology abroad and consider how these factors impact the adoption of the technology in the United States.

\section{COLLABORATORS}

Colorado School of Mines, NREL

RESEARCH GOAL

Create a visual tool to compare energy options by social,

environmental, and economic

factors that vary by locality.

\section{Distributional and Efficiency}

Impacts of Clean and Renewable Energy Standards for Electricity

\section{COLLABORATORS}

Massachusetts Institute of

Technology, NREL

RESEARCH GOAL

Combine a "top down" computable general equilibrium model and a "bottom up" electric-sector model to analyze the efficiency and distributional implications of a clean energy standard policy in the U.S. electric power sector.
IRAAP PROJECTS WITH SOCIAL AND BEHAVIORAL EMPHASIS

Power System Balancing with High Renewable Penetration: The Potential of Demand Response in Hawaii

COLLABORATORS

Massachusetts Institute of

Technology, NREL

RESEARCH GOAL

Using advanced modeling techniques and benchmarks for best practices in program design, examine cost effectiveness of demand response for balancing intermittent supplies.

Accelerating the Pace of Residential Energy Efficiency Retrofits

\section{COLLABORATORS}

Massachusetts Institute of

Technology, NREL

RESEARCH GOAL

Construct a model that predicts which homes might be good candidates for energy retrofit based on home heating costs.

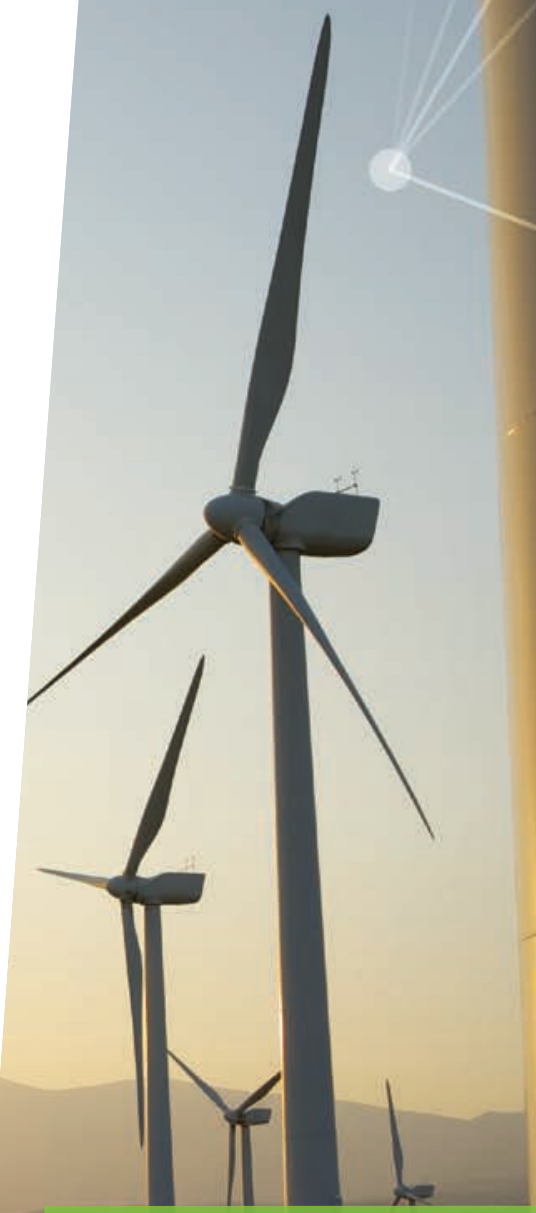

i LEARN MORE JISEA.org/iraap_about.cfm 


\section{JISEA'S GLOBAL_TEAM}

JISEA IS OPERATED

THE ALLIANCE FOR
SUSTAINABLE ENERGY,

LLC, ON BEHALF OF ITS
FOUNDING PARTNERS

\section{PROGRAM COMMITTEE}

JISEA's Program Committee William Boyd

direction to the executive director
and reviews and approves JISEA's

research agenda, priorities, and
annual research program plan.

Edward J. Balistrer

UNIQUE PERSPECTIVE

Prior to his entry into academics,
Balistreri worked as an economist

for the United States Internationa

simulation models of economic

global climate policy and

GNREL

0

Cojorado

State

顸

STANFOR D

W. University of Colorado

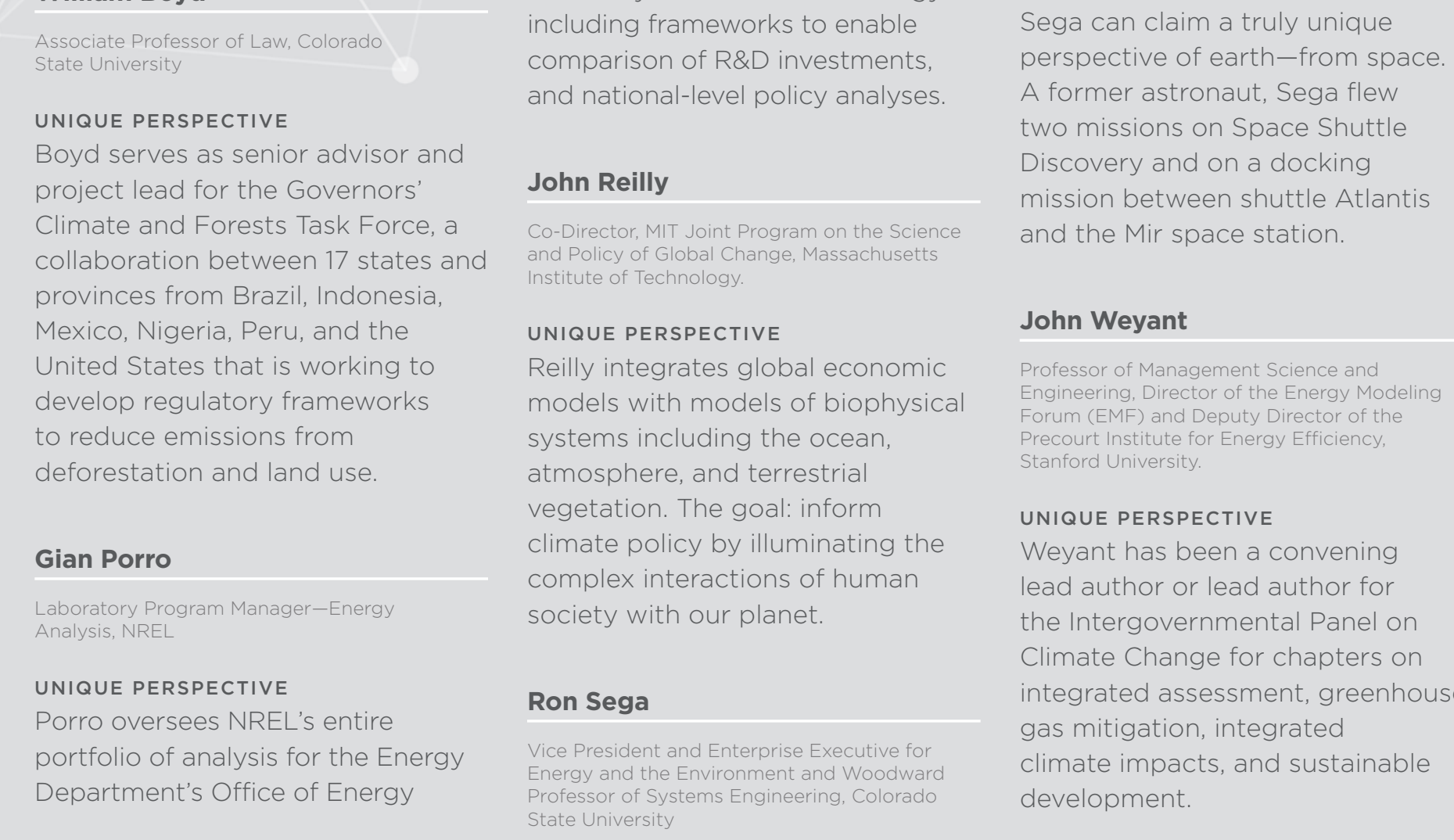

and

\section{RESEARCH AFFILIATES}

JISEA augments the capabilities of
its founding institutions with those

globe.

Eskom

ESKOM.CO.ZA

Eskom-Africa's largest electricity
producer-generates, transmits,

and distributes electricity to

industrial, mining, commercial
agricultural, and residential

customers and redistributes
South Africa and the region.

International Institute for Applied

Systems Analysis

SASACAT

|IASA researchers -200

mathematicians, social scientists
natural scientists economists

and engineers-develop.

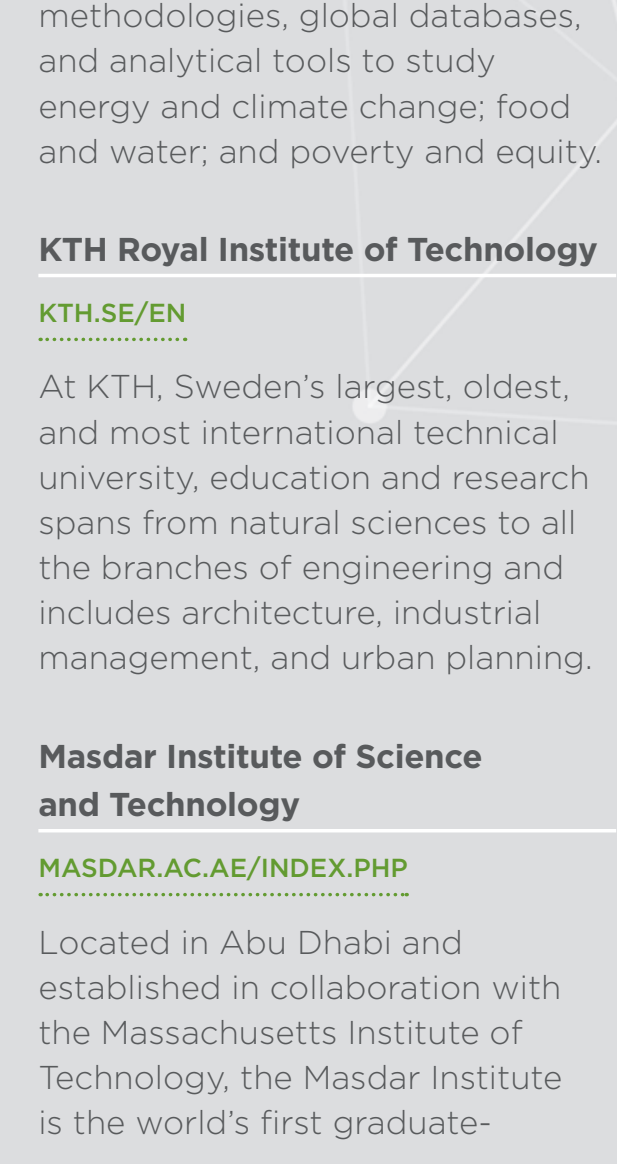

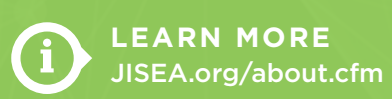

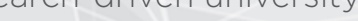

sustainable technologies that

leal-world solutions to issues

Renewable and Appropriate

RAELLEERKELEY.EDU

RAEL-a research, development

(poject minplementation, and

the University of California,

usstainable energy systems

energy networks. 


\section{REPORT CARD JISEA'S INCREASING IMPACT}

\section{SELECT PUBLICATIONS}

"Decision-making for High

Renewable Electricity Futures

in the United States."

Accepted for publication in Energy Strategy Reviews.

율 "Renewable Energy Potential on Marginal Lands in the United States."

Renewable and Sustainable Energy Reviews. January 2014

궅 "Power Systems Balancing with High Penetration Renewables: The Potential of Demand Response in Hawaii."

Energy Conversion and Management. December 2013.

"The Energy-Water-Food Nexus Through the Lens of Algal Systems."

Industrial Biotechnology. August 2013.
"CO Mitigation Potential of Mineral Carbonation with Industrial Alkalinity Sources in the United States."

Environmental Science \& Technology. June 2013

"Shale Gas in China: Prospects, Concerns, and Potential International Collaboration."

International Shale Gas and Oil Journal. Issue 1. 2013

"Natural Gas Scenarios in the U.S. Power Sector."

Energy Economics. November 2013.

Low Emission Development Strategies: The Role of Networks and Knowledge Platforms

JISEA technical report
RE-ASSUME: A Decision Maker's Guide to Evaluating Energy Scenarios, Modeling, and Assumptions.

Published by International Energy Agency - Renewable Energy Technology Deployment (IEA-RETD)

RES-E-NEXT: Next Generation of RES-E Policy Instruments.

Published by IEA-RETD.

(ㄱ.

Waste Not, Want Not:

Analyzing the Economic and Environmental Viability of Wasteto-Energy (WTE) Technology for Site-Specific Optimization of Renewable Energy Options

JISEA technical report.

\section{$H$}

"Interactions,

Complementarities and Tensions at the Nexus of Natural Gas and Renewable Energy" \#1 in the "Top 25 Hottest Articles" in The Electricity Journal during early 2013.

SCIENCE DIRECT 


\section{ON THE GLOBAL STAGE}

Doug Arent participated in a panel discussion at the Global Green Growth Summit 2013, which focused on the nexus of finance, innovation, and policy. Arent also presented at the Renewable Energy Finance Forum (REFF) West conference.

Morgan Bazilian contributed a foreword to the World Economic Forum's Global Energy Architecture Performance Index Report 2014. He joined the editorial board of Energy Research and Social Science and the Japan Renewable Energy Foundation's Innovation Network.

JISEA and the Colorado Center for Renewable Energy Economic Development led a discussion on challenges and opportunities of early stage energy investing at NREL's Industry Growth Forum 2013.

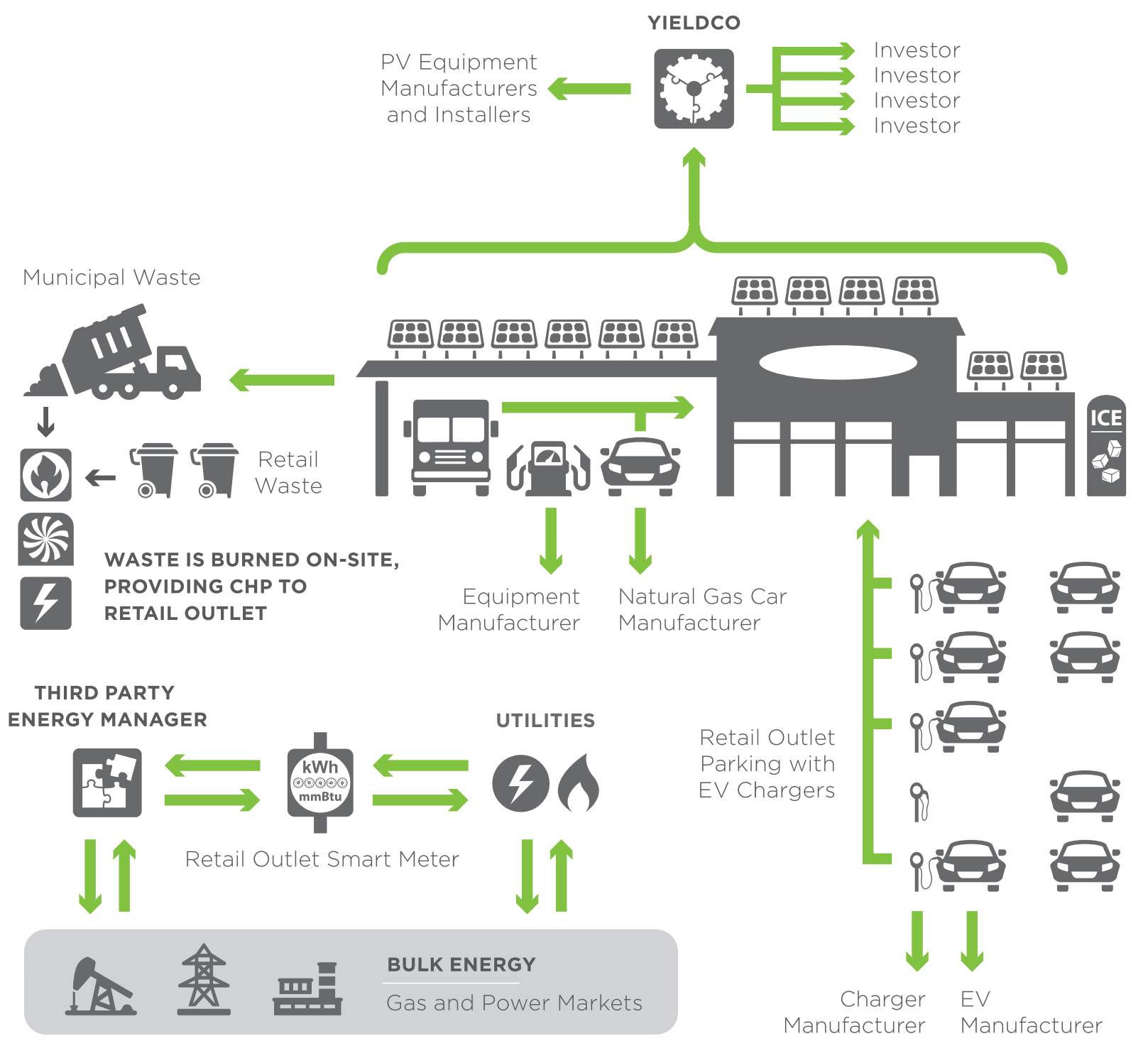

REVENUE FLOW

JISEA's research on energy solutions that include both natural gas and renewable energy garnered coverage in the New York Times, the Washington Post, Scientific American, USA Today, National Public Radio, and many other mainstream and scientific media outlets. This illustration from a 2014 published report shows potential revenue opportunities for retail stores, utilities, energy providers, car manufacturers, municipal waste firms, and many other businesses and service providers. 


\section{OUR SPONSORS}

JISEA is building a

global reputation for

value, quality, and

comprehensiveness

of its energy analysis.

Put our unique analytic

capabilities and

effective organization

to work for you.

JISEA appreciates and welcomes the support of all of our generous sponsors, including those who choose to remain anonymous.

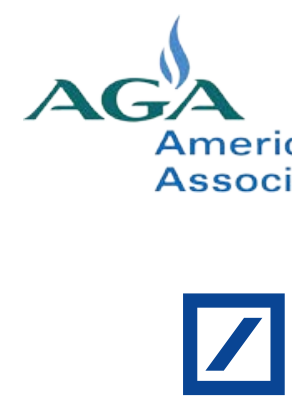

Deutsche Bank
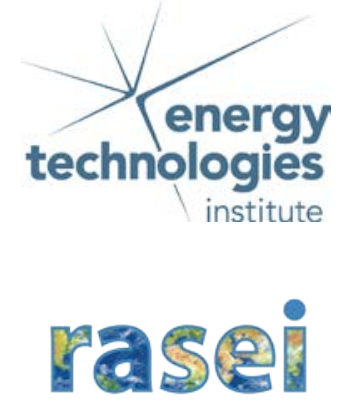
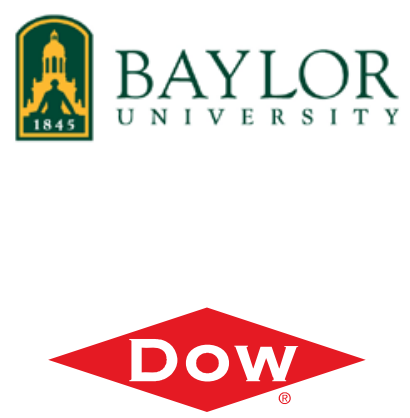

Lovells

SIEBEL

The Thomas and Stacey Siebel Foundatio
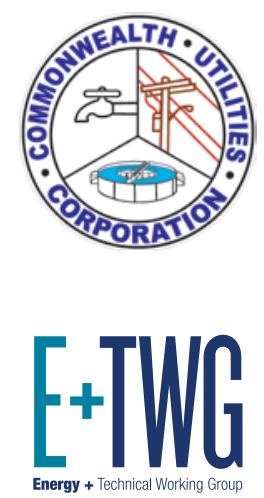

nationalgrid

THE POWER OF ACTION

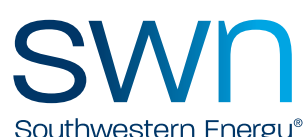

Southwestern Energy

\section{ConocoPhillips}

encana

natural gas

UBS

(i)

Contact JISEA program administrator Patricia Statwick at

opportunities. 
"JISEA has played a critical role in bringing much needed scientific research and objective analysis to the ongoing debate concerning the development of America's unconventional oil and gas resources. JISEA has also impressed me with their ability to assemble diverse stakeholder groups to engage in collaborative, 'problem solving' dialogues on a wide variety of energy issues. Southwestern looks forward to continuing our relationship with JISEA as we work to find the solutions for achieving a secure, lowcarbon energy future for our country."

\section{Mark Boling}

President - V+ Development solutions, General Counsel and Secretary Southwestern Energy

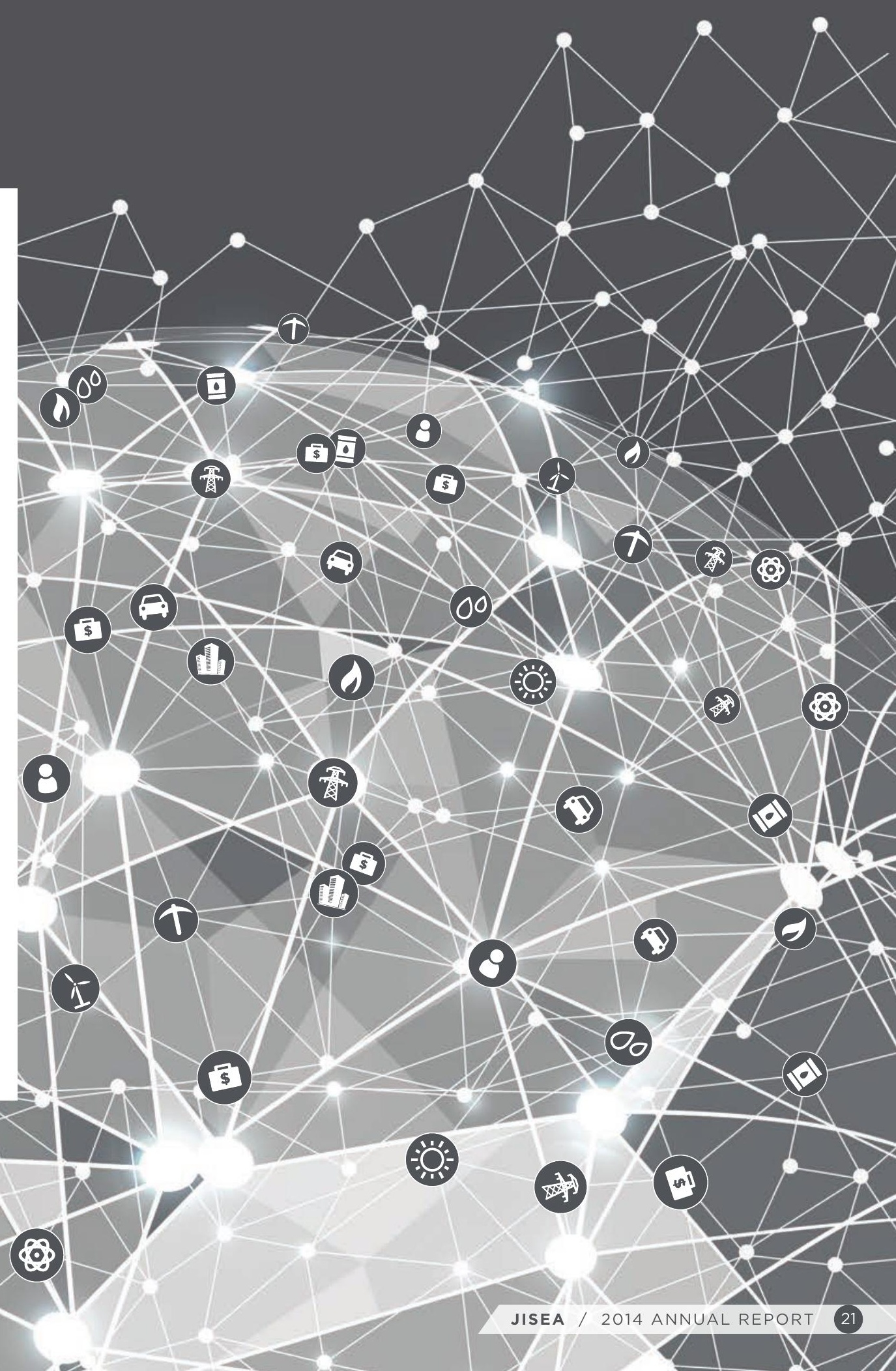


DANEL O coloradooschooloorMnEs

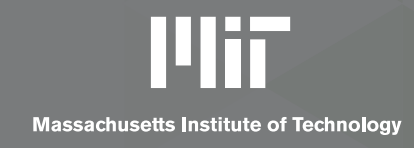

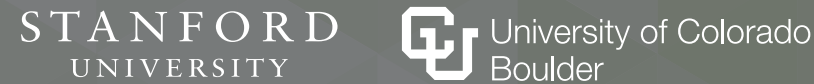

\section{JiSEA}

Joint Institute for
Strategic Energy Analysis

15013 Denver West Parkway

Golden, CO 80401

303-384-3767

JISEA.ORG
JISEA is operated by the Alliance for Sustainable Energy, LLC, on behalf of the U.S. Department of Energy's National Renewable Energy Laboratory, the University of Colorado-Boulder, the Colorado School of Mines, the Colorado State University, the Massachusetts Institute of Technology, and Stanford University.

NREL/BR-6A50-61126 | March 2014

Photo credits: inside front cover photos by Dennis Schroeder, NREL 20281 and NREL 20130; page 1 illustration by Peak Creative: page 2 from Shutterstock 141893215: page 3 by Dennis Schroeder. NREL 20130: page 4 by Dennis Schroeder, NREL 22072; page 6 from Shutterstock 102286060; page 8 from Shutterstock 133939916; page 9 Schroeder, NREL 22072; page 6 from Shutterstock 102286060; page 8 from Shutterstock 133939916; page 9
from Shutterstock 98985119; page 11 by Dennis Schroeder, NREL 28189; page 13 by Dennis Schroeder, NREL 20109; page 15 from Shutterstock 175323517; page 19 illustration by Dean Armstrong, NREL

Printed with a renewable-source ink on paper containing at least $50 \%$ wastepaper, including $10 \%$ post consumer waste. 